\title{
Public health investigation of swimming pool chlorine gas disinfection systems
}

\author{
J. Ivor Norlin* \\ Interior Health Authority
}

\begin{abstract}
In February 2012, a chlorine gas leak at a public pool facility in the British Columbia southern interior sent 70 people to hospital for assessment and treatment. As part of the follow-up investigation, the Interior Health (IH) public health engineering team undertook a comprehensive review of chlorine gas disinfection systems in public pools throughout the region. Deficiencies in the capacity to safely capture and release gas leaks were found in all 19 systems inspected. The engineering team subsequently worked with facility owners and area Environmental Health Officers to mitigate high-risk issues. However, less than half of the facilities were changed to on-site chlorine generation systems. Chlorine gas in public pool facilities poses an inherent risk to public health, and regional health authorities are responsible for routinely inspecting and overseeing these systems. The IH public engineering team continues to advocate for transitioning all public pool chlorine gas systems to less hazardous means of disinfection.
\end{abstract}

Key words: chlorine, gas, exposure, pool, public, inspection.

\section{Event summary}

The Interior Health Authority $(\mathrm{IH})$ provides health services for all residents in the southern interior of British Columbia (BC). With a population of over 730,000 , the IH region has 1,196 recreational pool facilities (see Figure 1) that are permitted under the BC Pool Regulation (2013). All these recreational pool facilities are supported by IH's Environmental Public Health department, which administers operating permits, issues construction permits for pool improvements, conducts routine inspections, and hosts safe pool operation training courses (Interior Health, 2018).

Chlorination is a cornerstone of safe pool water disinfection. Although several means for generating chlorine on site now exist, material costs and replacement of existing gas disinfection systems has led some pool operations to continue to use chlorine gas. There also continue to be private sector advocates for the use of chlorine gas (Thompson, 2015), despite the risks posed by chlorine gas to workers and the public who use the pools (Wilken et al., 2017).

In February 2012, a chlorine gas leak occurred at a community centre pool in the $\mathrm{BC}$ southern interior. The incident occurred during a swim meet and triggered an emergency evacuation. The quick actions of the pool operator minimized public exposure to the leaked gas. However, 45 children and 25 adults were sent to hospital for assessment and treatment. Subsequent investigation found a faulty valve caused inflowing water to become super saturated, resulting in chlorine gas releasing from the facility's wading pool.
Following the February 2012 chlorine gas leak, the IH public health engineering team undertook a review and inspection of chlorine gas facilities in other swimming pools throughout the region. The following documents the IH public health engineer's inspection methods, findings, and response.

\section{Chlorine gas inspections}

At the outset of the IH engineering team's initiative, there were 19 community pool facilities in IH with chlorine gas systems. Constituting less than $2 \%$ of all permitted recreational pool facilities in $\mathrm{IH}$ and located in communities spread across the region, individual health authority staff did not have experience from routinely inspecting chlorine gas disinfection systems. As such, a first key objective was to confirm inspection methods.

In undertaking a region-wide review, it was important to ensure consistent inspection practice. More importantly, the team needed to ensure safety when entering and assessing chlorine gas equipment. The engineering team engaged the local WorkSafe BC Officers who administer the BC Occupational Health and Safety Regulation (2018) for worker safety in chlorine gas disinfection facilities. A dedicated procedure was developed based on WorkSafe BC best practices (WorkSafe BC, 2009) (Figure 2), and the team provided training that included a webinar hosted by a WorkSafe BC Occupational Hygiene Officer.

A review of current best practices was conducted to inform a standard inspection protocol (Table 1). The engineering team

*Corresponding author: J. Ivor Norlin (email: Jvor.Norlin@interiorhealth.ca). 


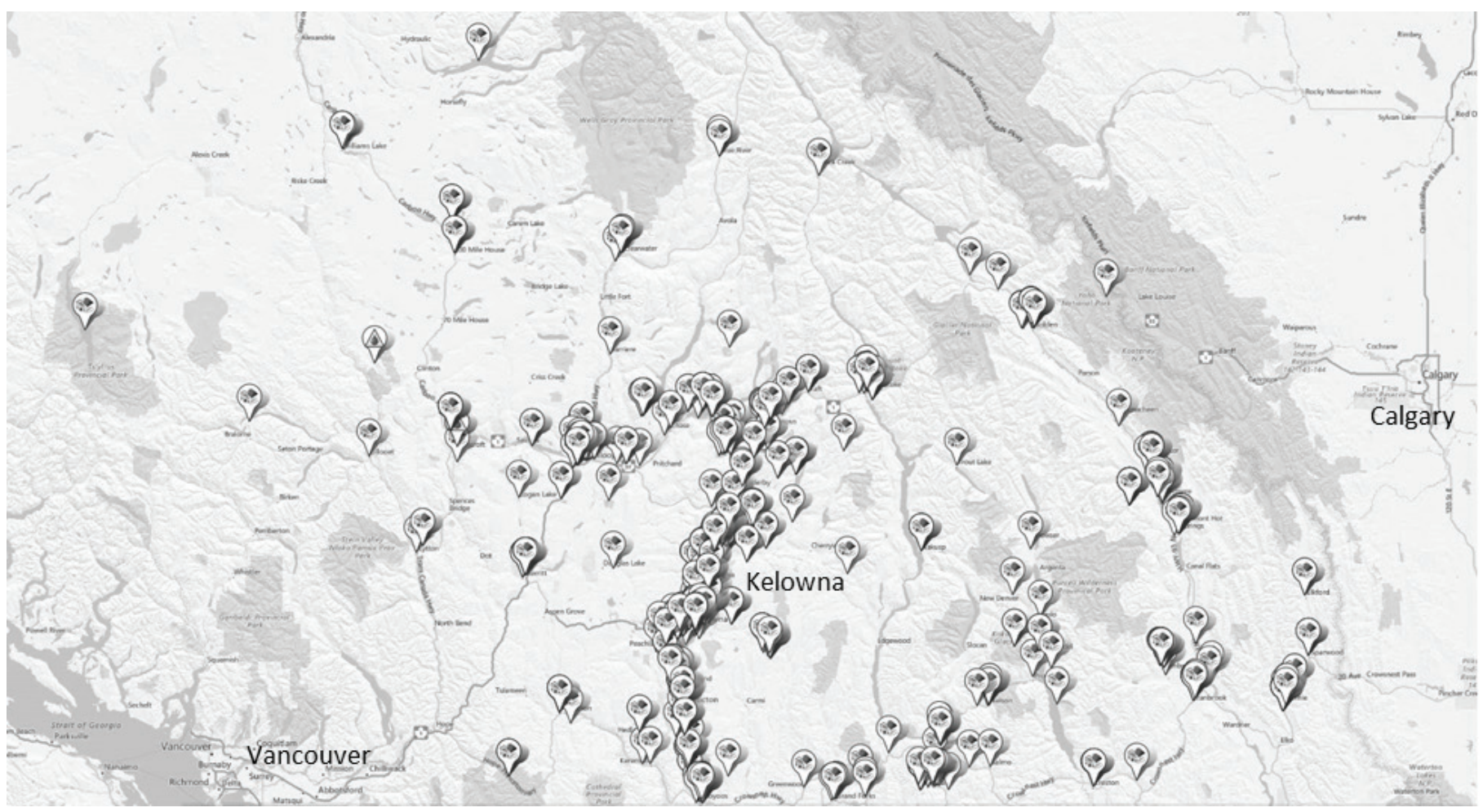

Figure 1. Map of permitted recreational pool facilities in BC Interior Health region.

\author{
Procedure for Entering Chlorine Gas Room: \\ The following steps must be taken before entering a chlorine gas room: \\ 1. Inform the owner of the facility of your plans to inspect the chlorine gas room and ask them to provide a \\ site hazard orientation including: \\ a. Confined and hazardous spaces \\ b. Any maintenance and repair activities \\ c. Noise exposure and emergency procedures
}

Do not enter a chlorine gas room if it requires confined space entry or if maintenance or repairs are occurring. Comply with the owner's direction for appropriate Personal Protective Equipment (e.g. hard hat, steel toed boots, safety glasses, hearing protection, high visibility vest).

2. Ensure you have an escape respirator in the form of a bite block respirator and are ready to use it.

3. Ensure the chlorine gas room is safe for entry by checking:

a. The facility has a chlorine gas sensor that is operational and connected to an alarm system

b. A viewing window for signs of a chlorine gas leak

c. The ventilation system is operating

Figure 2. Work safety procedure for inspectors entering chlorine gas facilities.

was involved in development of the inspection tool, with a training session provided on completion to ensure consistent application.

Inspection findings were documented with engineers ranking identified issues as high, moderate, or low risk in nature. The engineer was always accompanied by the area Environmental Health Officer (EHO) and wherever possible by the regional WorkSafe BC Hygiene Officer. Inspection findings were shared with the facility operator along with recommended actions for improvement. A frequently asked questions document was created to assist the team in explaining common chlorine gas system safety issues (Figure 3).

The 16 chlorine gas systems inspected in 2013 were all found to have deficiencies in their capacity to contain and safely release gas leaks. These deficiencies included: unsealed openings; discharge for exhaust not directed outdoors and away from air intakes and occupied areas; discharge duct not extended vertically up to at least $2.5 \mathrm{~m}$ above the roof; discharge or inlet dampers not air tight and corrosion resistant; and regulator pressure relief valve vent not directed outdoors, alarmed, and remote from air intakes and occupied areas. 
1. What are suitable dampers?

The BC Occupational Health and Safety Regulations state the employer must: "ensure that grilles providing makeup air from adjacent occupied areas are equipped with gas-rated, backdraft dampers". The term "gas-rated, back-draft damper" seems to be unknown to most in the HVAC industry. Rather, it is suitable to recommend use of dampers that are air tight and corrosion resistant. This meets the intention of our own practice to contain the chlorine gas within the room until it is safe to vent it. It may be difficult to identify the materials used in the damper construction once installed. Instead, look for signs of corrosion. If there is any doubt about the air tightness, it's recommend a smoke test be completed.

2. What is the approximate cost for automatic shut-off valves?

Emergency valve shutoff systems for both cylinders and tonners are manufactured by Halogen, Powell, and RoboControls. Maximum estimated the price for a Terminator emergency valve shutoff system for 2 cylinders is approximately $\$ 15,000$. This includes two valves and the control panel.

\section{How can an operator manually test their chlorine gas alarm?}

WorkSafe $\mathrm{BC}$ best practice is to test chlorine gas alarms monthly. This may be referred to as a "bump test". Ideally the process should be outlined in the chlorine gas sensor manual from the manufacturer. One way to do this is to mix a small amount (ex. 1 tbsp.) of vinegar and bleach in a paper cup or similar. Swirl the paper cup under the sensor opening. The gas alarm should come on.

4. What is the approximate cost to convert a pool facility from chlorine gas to hypochlorite?

Recent conversion of a public facility with a $25 \mathrm{~m}$ lap pool, kids' pool, and hot tub to hypochlorite was $\$ 20,000$. This conversion included a muriatic acid system.

5. Are "empty" chlorine gas cylinders really empty?

No. According to WorkSafe BC Chlorine Safe Work Practices, "Never assume a container is empty and therefore non-hazardous even though it may weigh empty."

6. What is the safe way to store "empty" chlorine gas cylinders?

"Empty" chlorine gas cylinders should be stored in an upright position, tagged "empty" and chained to a wall. They should be separated from full containers so that each can be accessed easily.

7. What are the better practices for operation of a ventilation system in a chlorine gas room?

The objective is to protect staff and public. This is achieved by staff operating the ventilation system whenever entering the chlorine gas room and controlled discharge of leaks to the environment. Ventilation systems should shut down in case of an alarm. The room can then be ventilated when the surroundings have been appropriately evacuated. This requires a hand-offauto switch.

\section{Should chlorine gas alarms include visible and audible alarms?}

Work Safe BC's Chlorine Safe Work Practices states, "The system must include a visible and audible alarm at the chlorine location, preferably connected to a radio or telephone system to alert the operator in case of emergency."

\section{Figure 3. Frequently asked questions about chlorine gas safety.}

When sharing inspection findings the engineers found that facility owners were often unaware of the issues or the associated risks. Education and discussion was required for the owners to understand the significance and the actions needed to address threats to public health. For example, one of the largest aquatic recreational facilities in the region had planned to replace chlorine gas with a hypochlorite system in the spring of 2013. The project was delayed because of budget concerns. In the fall of 2013 a system leak required a mass evacuation of the facility; thankfully, no one was injured. The owner subsequently found the money needed to move forward with changeover to hypochlorite.

Following the initial round of inspections in 2013, the engineering team inspected an additional three facilities and provided follow-up inspections through 2015. Pool owners developed plans and undertook improvements to address critical hazards and deficiencies, with six facilities choosing to convert to nongas chlorination systems. IH Environmental Public Health turned their attention to longer-term monitoring and oversight of the remaining gas chlorine facilities. A dedicated information system module was developed and integrated in the routine inspection activities of the IH recreational water program.

As of 2018, only one facility in the IH region had outstanding critical chlorine gas system deficiencies. Area EHOs track and follow up on gas systems issues as infractions in the IH information system, and the engineering team is called in to provide consultation and technical inspection as required. 


\section{Table 1: Comprehensive inspection list for chlorine gas disinfection systems}

\begin{tabular}{|c|c|c|c|}
\hline 1.0 & \multicolumn{3}{|l|}{ Chlorine room } \\
\hline 1.1 & Located above ground & 1.12 & Designated as a restricted work area \\
\hline 1.2 & Room is fully enclosed & 1.13 & Entry limited to authorized staff \\
\hline 1.3 & Separate from other rooms & 1.14 & Signs posted identifying hazards and precautions \\
\hline 1.4 & Panic hardware on door & 1.15 & $\begin{array}{l}\text { Shatterproof viewing window ( } 30 \mathrm{~cm} \text { or } 12 \text { " square or } \\
\text { larger) on to chlorine cylinders }\end{array}$ \\
\hline 1.5 & Door is lockable & 1.16 & $\begin{array}{l}\text { Safe means of testing conditions inside chlorine room } \\
\text { before entry }\end{array}$ \\
\hline 1.6 & Door is not self-locking & 1.17 & Continuous monitoring for chlorine gas leaks inside room \\
\hline 1.7 & Door opens outward & 1.18 & Light and exhaust switches easily identifiable \\
\hline 1.8 & Room has one exit that is external only & 1.19 & $\begin{array}{l}\text { Light and exhaust fan switches located outside of room } \\
\text { (may also be in room) }\end{array}$ \\
\hline 1.9 & Floor and walls are fire resistant & 1.20 & No floor drains \\
\hline 1.10 & $\begin{array}{l}\text { Construction and maintenance prevents chlorine gas leaks } \\
\text { from entering areas occupied by staff or public }\end{array}$ & 1.21 & Other chemicals are not stored in the chlorine room \\
\hline 1.11 & Openings are sealed & & \\
\hline 2.0 & \multicolumn{3}{|l|}{ Ventilation } \\
\hline 2.1 & $\begin{array}{l}\text { Exhaust fan is available for routine operator use and } \\
\text { emergencies }\end{array}$ & 2.6 & $\begin{array}{l}\text { Discharge duct extends vertically up to at least } 2.5 \mathrm{~m} \\
\text { above the roof (if near edge or } 6 \mathrm{~m} \text { (if in the middle of } \\
\text { the roof) }\end{array}$ \\
\hline 2.2 & $\begin{array}{l}\text { Intake for exhaust is near the floor and remote from door } \\
\text { and air inlet }\end{array}$ & 2.7 & $\begin{array}{l}\text { Discharge duct does not pass through other rooms } \\
\text { unnecessarily }\end{array}$ \\
\hline 2.3 & $\begin{array}{l}\text { Discharge for exhaust is directly out doors and remote from } \\
\text { air intakes and occupied areas }\end{array}$ & 2.8 & Discharge dampers are air tight and corrosion resistant \\
\hline 2.4 & Discharge duct is separate from other ducts & 2.9 & Intake grill is located on exterior wall near ceiling \\
\hline 2.5 & $\begin{array}{l}\text { Discharge duct is vapour proof, dedicated and chlorine } \\
\text { corrosion resistant }\end{array}$ & 2.10 & Inlet dampers are air tight and corrosion resistant \\
\hline 3.0 & \multicolumn{3}{|l|}{ Corrosion } \\
\hline 3.1 & Chlorine gas room does not contain nonessential equipment & 3.3 & $\begin{array}{l}\text { No condensation is present on chlorine gas cylinder or } \\
\text { other equipment }\end{array}$ \\
\hline 3.2 & Materials or finishes used are chlorine gas resistant & & \\
\hline 4.0 & \multicolumn{3}{|l|}{ Chlorine gas cylinder } \\
\hline 4.1 & $\begin{array}{l}\text { Protective hood in place when cylinder is not connected to } \\
\text { chlorinator }\end{array}$ & 4.5 & $\begin{array}{l}\text { Chlorinator designed to cease operation with shutdown } \\
\text { of booster pump }\end{array}$ \\
\hline 4.2 & $\begin{array}{l}\text { Cylinder is stored in an upright position, tagged if empty } \\
\text { and securely chained to the wall or weigh scale post }\end{array}$ & 4.6 & $\begin{array}{l}\text { Ability to shut off chlorine gas at cylinder remotely, } \\
\text { either manually or automatically due to alarm, with } \\
\text { notice to operator }\end{array}$ \\
\hline 4.3 & Suitable weigh scale in use for active connected cylinder & 4.7 & $\begin{array}{l}\text { All piping carrying chlorine gas or liquid is identified } \\
\text { according to WHMIS requirements }\end{array}$ \\
\hline 4.4 & Valve stem wrench in place for connected cylinders & 4.8 & Not located close to a heat source \\
\hline 5.0 & \multicolumn{3}{|l|}{ Regulator } \\
\hline 5.1 & $\begin{array}{l}\text { Regulator pressure relief valve vent is directed outdoors, } \\
\text { alarmed and remote from air intakes and occupied areas }\end{array}$ & 5.2 & $\begin{array}{l}\text { Regulator is located as close as possible to the } \\
\text { cylinder head }\end{array}$ \\
\hline 6.0 & \multicolumn{3}{|l|}{ Ejector } \\
\hline 6.1 & Chlorine Gas ejector is located within the chlorine room & & \\
\hline 7.0 & \multicolumn{3}{|l|}{ Maintenance } \\
\hline 7.1 & $\begin{array}{l}\text { The chlorine room has been smoke or pressure tested since } \\
\text { construction }\end{array}$ & 7.5 & Chlorine gas alarm has been tested within the last month \\
\hline 7.2 & $\begin{array}{l}\text { The fan, motor and airflow for the exhaust system has been } \\
\text { checked regularly to ensure satisfactory operation }\end{array}$ & 7.6 & $\begin{array}{l}\text { Chlorine gas alarm system has been maintained in } \\
\text { accordance with manufacturer's instructions }\end{array}$ \\
\hline
\end{tabular}


Table 1. (continued).

\begin{tabular}{|l|l|l|l|l|}
\hline 7.3 & \multicolumn{1}{|l|}{$\begin{array}{l}\text { The flexible chlorine gas line from the chlorine regulator to } \\
\text { the ejector has been replaced within the last 2 years and } \\
\text { tagged with date of last replacement }\end{array}$} & 7.7 & Facility has wind sock in vicinity of exhaust fan outlet \\
\hline 7.4 & $\begin{array}{l}\text { Chlorine gas alarm system has been calibrated within the } \\
\text { last year }\end{array}$ & & \\
\hline $\mathbf{8 . 0}$ & Gas sensor & \multicolumn{2}{|l|}{$\begin{array}{l}\text { Gas sensor is located near floor level and remote from } \\
\text { the door, inlet to ventilation exhaust and regulator } \\
\text { pressure relief valve vent }\end{array}$} \\
\hline 8.1 & Gas sensor is connected to suitable alarm system & 8.4 & $\begin{array}{l}\text { Alarm equipment, except sensor, is located outside of } \\
\text { chlorine room and near the viewing window }\end{array}$ \\
\hline 8.2 & Sensor is located inside the chlorine room & 9.4 & Written emergency response procedures are available \\
\hline $\mathbf{9 . 0}$ & Emergency response & 9.5 & Staff is well trained \\
\hline 9.1 & Staff has access to personal protective equipment (PPE) & 9.6 & Emergency response procedures are practiced \\
\hline 9.2 & Staff know how to use PPE & $\begin{array}{l}\text { Written work procedures are available for routine operation } \\
\text { and maintenance }\end{array}$ &
\end{tabular}

\section{Discussion and future challenges}

The chlorine gas incident in February 2012 triggered the IH public health engineering team into taking proactive action to seek out, assess, and support improvements of all chlorine gas systems serving public pool facilities in the $\mathrm{BC}$ southern interior. This initiative was successful in reducing risk to public and left a legacy of improved inspection protocols, documentation, and inspection safety. However, the February 2012 incident and subsequent $\mathrm{IH}$ initiative also showed the inherent risks to public health associated with chlorine gas in public recreational facilities. The valve failure that resulted in the February 2012 gas release occurred despite the operator having followed appropriate assessment and maintenance practices. Chlorine gas is inherently dangerous, and there is no way to completely remove this risk without converting to some other means of disinfection.

The number of public pools with chlorine gas systems in the $\mathrm{IH}$ region is relatively small. Chlorine gas disinfection systems are more commonly found in the community drinking water treatment plants across the region. Drinking water system operators are typically highly trained in chlorine handling, but there still exists a risk of gas leaks in these treatment facilities. However, the risk posed by these plants is lower as public access is restricted and drinking water treatment plants are not normally located in residential areas. By contrast, community aquatic facilities are located in residential and business areas. The implications of deficient chlorine gas capture and release systems for broader community safety and emergency response (i.e., for surrounding neighbourhoods) was a common point of discussion within the $\mathrm{IH}$ engineering team and with local government representatives.

Focused training for the engineering team to support safe and consistent inspection of chlorine gas systems was a valued aspect of the initiative. However, the team found follow-up with operators challenging. The role of a Public Health Engineer does not include routine inspection and administration of public health law. As such, coordination with environmental public health professionals to support and hold operators accountable to address identified critical hazards was critical for the initiative's success.
Several community aquatic facility owners were resistant to acknowledge the identified chlorine gas hazards and make improvements to their systems. Critical hazards remained outstanding in these communities for years following the initial inspections by the IH engineering team in 2013-2014. In October 2017 an ammonia leak occurred at a hockey arena in another small community in the $\mathrm{IH}$ region that killed three workers. In the wake of this tragedy, communities paid for independent safety assessments of their ammonia and chlorine gas systems. The findings of the independent reports mirrored the IH inspection results, and the previously resistant facility owners allocated the funding needed to make the necessary improvements to their chlorine gas systems.

The authority to ban chlorine gas comes from provincial legislation. As a regional health authority, IH cannot prevent the use of chlorine gas in public pools. The role of regional health authorities under the provincial Pool Regulation is to continue to provide routine inspection and respond to incidents at these facilities. Though not directly responsible for ongoing inspection and compliance of public swimming pools, the IH public health engineers have taken it as their professional responsibility to continue to advocate for transition to inherently less hazardous on-site chlorine generation systems throughout the region.

\section{References}

Interior Health. 2018. Recreational water: Keeping your public swimming pools and beaches safe [Online]. Available at: https://www. interiorhealth.ca/YourEnvironment/RecreationalWater/Pages/ default.aspx [accessed 29 November 2018].

Occupational Health and Safety Regulation, Reg.143/2017. 2018. Available at: Province of British Columbia Queen's printer website: http://www.bclaws.ca/civix/document/id/complete/statreg/ 296_97_00 [accessed 6 December 2018].

Pool Regulation, Reg. 240/2015. 2013. Available at: Province of British Columbia Queen's Printer website: http://www.bclaws.ca/ civix/document/id/complete/statreg/296_2010 [accessed 6 December 2018]. 
Thompson, K. 2015. Chlorine gas is an old public health ally. Environmental Science \& Engineering Magazine, July/August 2015, pp. 20-21.

Wilken, J. A., DiMaggioni, M., Kaufmann, M., O’Connor, K., Smorodinksky, S., Armatas, C., Barreau, T., Kreutzer, R., and Ancheta, L. 2017. Inhalation chlorine injuries at public aquatic venues - California, 2008-2015. Morb Mortal Wkly Rep. 66(19): $498-501$

WorkSafe BC. 2009. Chlorine safe work practices, p.44. ISSN 1705298X. Available at: Province of British Columbia's Work Safe BC website: https://www.worksafebc.com/en/health-safety/hazardsexposures/chlorine 